\title{
EL PEÑÓN DE VÉLEZ DE LA GOMERA EN 1743: LA CIUDADELA Y LA PESTE NEGRA
}

Vicente Moga Romero 


\section{LA CIUDADELA}

"Vuele mi pluma fuera de la esfera de su fortaleza..."

El contagio de El Peñón es un libro escrito en 1744 en el Peñón de Vélez de la Gomera, con ocasión de la epidemia de peste negra producida en el presidio. Redactado por tres médicos, desplazados especialmente desde Málaga al Peñón, es esencialmente un pequeño tratado médico, con un interesante trasfondo histórico, que conserva el doble interés de situarnos en la difícil coyuntura de una época, y un lugar, todavía sometidos a los vaivenes de las epidemias periódicas, y de implicarnos en la lectura de un mundo cercano al de Melilla. Curiosamente, la escasa territorialidad del Peñón de Vélez de la Gomera, apenas un islote rocoso, unido al continente africano, por un istmo arenoso formado en 1930, nos ubica a través de un ensayo médico, en la escala planetaria del siglo XVIII.

En la actualidad, el Peñón de Vélez de la Gomera, forma parte de los territorios españoles de la ribera sur del Mediterráneo, junto a la isla de Alhucemas, la isla de Alborán, el archipiélago de las Chafarinas, y las ciudades de Ceuta (que incluye la Isla del Perejil) y de Melilla. Asiento de una pequeña guarnición militar, es sin duda una ciudadela sugerente y única en el Mediterráneo. Una especie de Monte Saint Michel, sin catedral, sin grandes mareas y sin turistas, pero con el enorme atractivo de su historia y su situación, frente a las costas epicéntricas del Rif, a poniente de Alhucemas, y a algo más de cien kilómetros al oeste de Melilla, y a unos ciento cuarenta kilómetros al oriente de Ceuta.

Las reseñas actuales del Peñón son escasas y una guía tan documentada, en general, como las de la colección "Les guides bleus", nos dice solamente que "a $5 \mathrm{~km}$ E de Torres de Alcalá (pista difícil, en cornisa) se encuentra la aldea, antigüamente próspera de Badis, enfrente del Peñón de Vélez de la Gomera, islote de soberanía española unido a la costa por una lengua de arena de un centenar de metros, en un paraje soberbio" (Maroc: 176). Sin embargo, otras publicaciones, también recientes, expresan que el Peñón "constituye uno de los rincones y fortalezas más subyugantes de todo el Mare Nostrum... parece sacado de la literatura fantástica. Es como un aguafuerte de Doré... El conde de Montecristo, por ejemplo, pudo muy bien haber penado allí". (Pallares: 53). 
Esta última es también mi opinión. El viaje de Melilla al Peñón, no es sólo una enciclopedia de historia viva, sino la emoción de vivir un paisaje anacrónico, enraizado en lo intemporal, humano y de gran belleza. El Rif, oteado por la isla de Alhucemas y el Peñón, nos entrega siempre estampas impresionistas en los otoñales valles de almendros que jalonan el camino hasta Vélez. El Rif parece, entonces, empeñado en situar su imponente estructura montañosa como barrera del Mediterráneo. Claro que la visión, casi al término del viaje, de la playa de Cala Iris, de los restos de la fortificación española de Torres de Alcalá, y del propio Peñón, desmorona cualquier barrera. No es ya solamente observar la realidad de un Peñón casi mítico y borgiano, es también la emoción de revivir la ciudad de Bades, puerto natural del Reino de Fez, hasta la Baja Edad Media (Cressier: 46), y el silencio, perfumado de pinos, de uno de los parajes más hermosos del Planeta.

El Peñón de Vélez de la Gomera es una entelequia. Apenas una roca de escasos setenta y siete metros de altura, de forma triangular, con doscientos veinte metros de máximo entre vértices, parece, desde el aire, un león en ejercicio barroco de marinería, a escasos ochenta metros del continente africano. Su nombre proviene de la ciudad a la que desplazó, en 1508, cuando el Conde Pedro Navarro lo conquistó. De "Deyrat Bedis" tomó su nombre del Peñón, y lo completó con el de la tribu Ghomara, pobladora de la costa rifeña. Su historia es un recorrido laberíntico de más de cuatro siglos, estremecido por secuencias inolvidables de catástrofes casi bíblicas: terremotos, temporales, plagas de langosta, epidemias de colera, fiebre amarilla, peste negra, etc. Isla al margen de un continente es también un intento marginal de existencia.

Conquistado bajo Fernando el Católico, el 23 de julio de 1508, fue perdido el 20 de diciembre de 1522, en una "mágica" operación que incluía a "dos moros, famosos alquinistas de Fez" transmutadores de la codicia en perfecta plata (Estrada: III,533) y un desengaño amoroso. "Perdido el Peñón, se sintió mucho en España, por la comodidad, que de allí en adelante tendrían los moros para sus bajeles y correrías en la Costa, como antes lo hacían" (Estrada: III,535). La realidad es que España, con su red de presidios - los tres denominados "menores": Peñón, Alhucemas y Melilla; y el presidio mayor de Ceuta- había conseguido asfixiar la salida al Mediterráneo de lo que habían sido las rutas comerciales del Reino de Fez en la Edad Media. (Zaïm : pessim)

En 1564 de nuevo España ocupa el Peñón, como consecuencia de una expedición de gran envergadura, que lo incorpora desde entonces a la corona de Castilla. Lo que no quiere decir que cesara el hostigamiento de los rifeños y los sultanes marroquíes, ya que, al contrario, el Peñón será un enclave constantemente hostigado por los "fronterizos".

Ya en la época del libro que nos ocupa, contemplamos: "su población está en forma de anfiteatro, con una calle que da dos vueltas, empezando desde la Puerta del Varadero, con sus rastrillos, defendida del Baluarte de la Trinidad, 
saliendo una punta de piedra hacia la tierra firme, que llamada la Isleta, donde está el Fuerte de San Antonio, que es el más inmediato al enemigo.

Entrado por dicha Puerta del Varadero se encuentra el Polvero, con muralla moderna, y su batería de cañones..." (Estrada III,543).

El Peñón, incluía en su minúsculo territorio, tres aljibes para recoger el agua de lluvia, ya que se carecía de ella, el cuartel de los desterrados en la llamada "Punta de la Baba", almacenes de víveres, a menudo vacíos, y las casas familiares, incluida la del gobernador, el hospital, junto al Baluarte de San Julián, la iglesia parroquial, con vicario y cura (Estrada: III, 543 y ss).

El Peñón estaba habitado en la época de desarrollo de la peste por 46 vecinos, que suponen unas 150 personas, según los datos obtenidos de la "renta del tabaco" de 1745/1747 (Sanz: 110). Esta misma renta establece 100 vecinos para Melilla, 38 para Alhucemas y 874 para Ceuta. Ya en 1758 tenemos un desglose más exacto de los habitantes del Peñón: 177 militares; 190 desterrados y el resto de habitantes, que hace 143. En total 510 habitantes, con una relación población/ desterrados del $37,2 \%$. En cuanto a los demás presidios, las cifras de este periodo dan: Melilla, con 2.000 habitantes; Alhucemas, con más de 700 habitantes; y Ceuta, con más de 8.000 habitantes. (Sanz: 109).

Los principales problemas para el Peñón residían en las graves dificultades de abastecimiento, y en la carencia de agua. Las arriesgadas salidas de los "isleños", para buscar higos chumbos, cazar palomas, pescar, realizar las cortas de leña, o recoger agua, reportaron a la historia del Peñón una larga lista de muertos. Basta citar, con Pascual Madoz, la hambruna sufrida en 1812 que impelió al gobernador a echar "al campo del moro 150 presidiarios para aligerar de gente a la que encerraba el Peñón" (Madoz: 212).

En estas condiciones las incidencias de una epidemia de peste negra podían ser dramáticas. El abandono coyuntural de los presidios, bajo Felipe $\mathrm{V}$ (17001746) y algunas normativas, como la real disposición de 1731, que prohibía la compra de víveres y otros géneros, para los habitantes del Peñón, a las embarcaciones extranjeras que lleguen a la Isla, hacian que la efectividad de los Presidios menores sea puesta en duda ya que "la considerable extensión de costas que desde el Peñón hasta Tres Forcas posee el Rif; no pueden cerrarse con sólo establecer tres puntos aislados, mal provistos de embarcaciones y sin lazos seguros de unión entre sí ni con España" (Pezzi: 34-35).

La provisión de bastimentos, se centralizaba en Málaga, y con la presencia de un asentista, que suministraba las raciones de armada, así como armas y los géneros para todas las dependencias. Por cierto que el Rey hacía frente al mantenimiento de los presidios africanos; en palabras del historiador melillense J. A. de Estrada, con "la limosna de las Bulas, Subsidio y Excusado, y las demás Gracias". 


\section{LA PESTE NEGRA}

"Padecieron en esta Fuerza [del Peñón de Vélez de la Gomera] un mal epidémico de ciertos landres o granos el año de 1744 y 1745 con motivo de un pingue que llegó a Ceuta infectado de este contagio, del que murieron varias personas, las más soldados y desterrados y unos religosos de San Juan de Dios, que pasaron con la mayor edificación a la asistencia de los enfermos"

Juan Antonio de Estrada.

Población general de España... Madrid, 1748, v. III, p. 550-551.

Escasez de avituallamiento, falta de agua, y las circunstancias climáticas van a provocar una serie de epidemias de todo tipo. Gabriel de Morales, en sus Efemérides y curiosidades: Melilla, Peñón y Alhucemas, extraídas de fuentes documentales primarias, como los libros parroquiales, nos ha dejado constancia de la letanía de invasiones epidémicas (Morales: passim):

* 3 de Octubre de 1706: Comenzó una epidemia de tal importancia, que desde este día hasta el 6 de Diciembre murieron 40 personas, aproximadamente la noventa parte de la población total. No sabemos cual fue la enfermedad que la motivó.

* 5 de julio de 1743: Comenzó la epidemia de landre (peste bubónica) que desde el 7 de este mes hasta el 4 de noviembre hizo 50 víctimas. La población total de la plaza no llega a 250 habitantes.

* 20 de enero de 1744: En este día, fiesta de San Sebastián, se dio por terminada la epidemia de peste bubónica.

* 15 de octubre de 1745: Se reprodujo la epidemia de landre (granos malignos) que infestó la población de 1743-1744.

* I5 de abril de 1754: Nuevamente hacía estragos en el Peñón la epidemia de escorbuto y no había médico, ni medicinas.

* 2l de julio de 1799: Padecía el Peñón una fuerte epidemia de escorbuto y no tenía médico: de Málaga se le envió uno; en noviembre no había terminado todavía la epidemia. 
* 19 de noviembre 1799: Padecía la Plaza una fuerte epidemia de escorbuto.

* 6 de febrero de 1800: La Plaza padecía una epidemia de escorbuto y le faltaban agua, víveres y medicina.

* 10 de agosto de 1801: Comenzó la plaza a sufrir una epidemia de fiebre amarilla importada de Alhucemas.

* 23 de noviembre de I821: la Plaza sufía dos epidemias, fiebre amarilla y escorbuto, carecía de víveres y medicina y el gobernador le envió algunas de estas y 12 carneros.

* 15 de enero de 1822: Envío de donativos (alimentos y medicina) para la epidemia de escorbuto.

* 31 de julio de 1832: Entre los confinados hacía estragos el escorbuto: llevaban dos meses a ración de habichuelas solamente.

* I de diciembre de 1833: Comenzó a sentirse una epidemia de cólera, que duró todo el mes.

Con esta relación de epidemias, seguía vigente el adagio medieval que imploraba "del hambre, de la peste y de la guerra, líbranos Señor". Esta temible trilogía se hacía, en muchos periodos de la historia del Peñón acumulativa. Ya hemos visto que el desabastecimiento de la Plaza llevaba, en ocasiones demasiado frecuentes. a situaciones extremas; por otro lado, era incesante el hostigamiento de los rifeños desde la costa próxima; y, por último, las epidemias también visitaban el Peñón.

Las grandes epidemias generales - pandemias - se habían producido en Europa en los años 1128, 1358-1360; 1373-1375. Durante el siglo XVI se produce un descenso de las epidemias, que, sin embargo, vuelven a incrementarse en el siglo XVII. Ya en el siglo XVIII la peste empieza a ser erradicada de Europa, produciéndose epidemias esporádicas, como la de 1742 en Italia, la de 1771 en Polonia y la de 1785 en Hungría. Este descenso epidémico no significa su total desaparición, fuera del continente europeo. Lejos de ello, como hemos visto en la relación anterior, el siglo XIX fue proclive a las epidemias. Ello impulsaría la literatura médica tendente a combatirla al menos teóricamente en puertos españoles vitales para el abastecimiento de los presidios menores, como el caso del puerto de Málaga (Arénjula). Igualmente, otros puertos, con tradición comercial en el Norte de Africa, como Marsella, se verían maltratados por la epidemia. En Septiembre de 1903, el periódico melillense "El Telegrama del Rif", informaba de la interrupción de las comunicaciones marítimas con Marsella, debido a la epidemia de peste bubónica sufrida por esta ciudad francesa.

Todavía a mediados del siglo $\mathrm{XX}$, existían focos endémicos de peste en el Norte, Noroeste y Sur de Africa. Recordemos la epidemia argelina de 1930, que inspiró la novela de Albert Camus, La peste, publicada en 1947, y que se desarrolla durante la epidemia de peste en la ciudad de Orán. 
Desde la cuestionada "peste de los filisteos" (1400 a. C) hasta los años 1950, la peste había quizás ya generado un mecanismo humano de autodefensa e inmunización, que incidiría en el notable descenso de su impacto mundial, quedando relegada a zonas muy caracterizadas. Es ya en 1894, cuando el suizo Yersin descubre, durante una epidemia en Hong-Kong, el bacilo de la peste (denominado desde entonces como Bacilo de Yersin, pasteurelle pestis, o, yersinia pestis), conociéndose ya que la peste forma parte de las enfermedades infecto-contagiosas.

También se conocía que la peste se manifiesta bajo tres formas inconfundibles: a) la bubónica, con abultamientos o bubones en determinadas zonas del cuerpo; b) la pulmonar, resultado de la infección directa de los pulmones; c) la septicémica, la más grave, y que produce hemorragias cutáneas por todo el cuerpo de color negro. Esto ha dado el nombre de "peste negra" a la temible enfermedad.

Igualmente es conocido el mecanismo de transmisión, que es fundamentalmente a través de los roedores y, sobre todo, de las ratas, pero también de las ardillas, jerbos, marmotas, etc. Las ratas son las más frecuentemente infectadas y mediante la pulga transmiten la enfermedad al hombre y a otros animales. Esta cadena de destrucción se ve favorecida por determinadas condiciones climáticas de calor y humedad, que, en el verano de 1743, estaban aseguradas en el Peñón de Vélez.

Todos estos conocimientos permiten hoy combatir cualquier brote epidémico mucho mejor que en el siglo XVIII. Sobre todo por la adopción de medidas preventivas de sanidad e higiene.

Un ejemplo cercano de ello lo tenemos en la propia Plaza de Melilla a finales del siglo XIX , cuando la irrupción de una epidemia de peste negra en la ciudad lusa de Oporto, lleva a tomar unas precauciones sanitarias a toda España, incluida Melilla.

La epidemia pestífera de Oporto, en 1899, lleva a la Secretaría de Sanidad del Gobierno Civil de la Provincia de Málaga, a dictar una circular, publicada en el Boletín Oficial de la Provincia de Málaga, número 40, del 16 de agosto de 1899. En esta circular se impelía a las Juntas Locales de Sanidad a proponer a los alcaldes tomar las precauciones necesarias al caso. En Melilla, es el jefe de sanidad de la Plaza, quien por medio del Comandante General Interino, informa al General Presidente de la Junta de Arbitrios de Melilla, e indica las actuaciones recomendables, tal como a continuación recogemos; en transcripción del documento que se custodia en el Archivo Municipal de Melilla (Junta de Arbitrios, Caja № 28):

"Excmo. Sr.:

El Jefe de Sanidad militar de esta Plaza en 25 del actual me dice lo que 
sigue. Excmo. Sr. La amenaza para España de verse invadida de la peste bubónica desarrollada en Portugal ha dado lugar a que por las autoridades de la Península se adopten medidas de precaución a fin de evitar el peligro o aminorar sus efectos en el caso desgraciado de presentarse.

Nuestra contínua y precisa comunicación con la Península hace que nos hallemos en esta Plaza amenazados de los mismos peligros y que por lo tanto debamos adoptar las mismas precauciones. Ya se observa Excmo. Sr. el más riguroso cuidado con cuantos pasajeros, ganado y géneros son importados por mar, a fin de cerrar esa vía a la enfermedad, pero sería conveniente adoptar dentro de la población medidas sanitarias encaminadas a colocar la Plaza en las mejores condiciones higiénicas posibles. Cumplo por lo tanto un deber al dirigirme a V. E. hoy proponiéndole la adopción de las siguientes medidas encaminadas a este fin:

Primera. Seria conveniente hacer frecuentes visitas domiciliarias en todas aquellas casas que se juzgue conveniente, obligando a los propietarios y vecinos a adoptar medidas higiénicas las más precisas por el momento y otras menos precisas con más tiempo. Para el mejor y más rápido resultado de estas visitas podría dividirse la población en zonas bajo la vigilancia de un médico cada una de ellas y con la intervención en todas del médico titular, de los médicos mayores y del jefe que suscribe.

Segunda. Igualmente sería conveniente evitar que dentro de las viviendas, que para ello no tuvieren condiciones, se albergaren animales domésticos y someter además a estos a la observación del señor subdelegado de veterinaria.

Tercera. Hacer con el mayor escrípulo posible el reconocimiento de sustancias alimenticias a fin de evitar el consumo de las adulteradas o en mal estado de conservación.

Cuarta. Recomendar la más exquisita limpieza y aseo tanto en ropas como en los individuos.

Quinta. A ser posible desaparezca de la población todo el enjambre de individuos que en ella existe que sin medios de subsistencia viven hacinados en viviendas sin ventilación, y comiendo poco y mal, merced unas veces al sobrante de rancho de los cuarteles y otras de la caridad pública.

También sería conveniente Excmo. Sr. estar prevenidos para cualquier contingencia y tener al menos indicados dos locales, uno para lazareto de observación y desinfección y otro para hospital de atacados, en el caso desgraciado que la epidemia llegare a desarrollarse, y adquirir suero antipestoso a ser posible.

Estas son Excmo. Sr. las más apremiantes medidas que me honro en proponer a V. E. por si las estima oportunas.

Lo que traslado a $V$. E. para su conocimiento a fin de que se sirva ordenar se pongan en vigor las medidas que propone el jefe de sanidad de esta Plaza.

Dios guarde a V. E. muchos años.

Melilla, 28 de agosto de 1899. El Comandante General Int.․: Salinero". 
Aunque también en el Siglo de las Luces se adoptaban precauciones sanitarias, e incluso en épocas muy anteriores. Recordemos, por ejemplo, que el origen de los lazaretos (es decir, hospitales situados en las afueras de las poblaciones, donde se realizaba la cuarentena a los sospechosos de peste) se produce con la irrupción de las grandes pandemias del siglo XIV en Europa. Estas medidas preventivas eran también habituales en el Peñón. Así, la llegada el 15 de junio de 1677, al Peñón de un barco con gente de Orán —-donde había peste- obligó a los que desembarcaron a guardar cuarentena en la Cueva de los Caballeros (Morales: 357). Lo mismo solía hacerse con los refugiados moros en el Peñón.

Otras medidas propiamente de higiene podrían adoptarse, pero la escasez de agua en el Peñón, no ayudaba a ello. Además, la promiscuidad en la que se vivía y la presencia numerosa e incontrolada de perros, gatos y roedores, agravaba la situación sanitaria de la Plaza. Los médicos expresaban sus quejas a este respecto, ya que incluso los barcos que amarraban en ella solían dejar uno o dos perros (Morales: 356). Pero, cuando faltaban las vituallas, los perros, así como los gatos y las ratas, eran bocado de presidio. Por supuesto, soldados y presos, serán los que sufrirán más duramente las catástrofes abatidas sobres el Peñón, al ser los grupos sociales más desfavorecidos.

Las medidas preventivas se incluyeron también en el propio Peñón, por los médicos enviados por la Junta de Salud de Málaga, a petición del gobernador de la plaza, que desde el principio intentaron preservar a la población sana y curar a la afectada. Ellos mismos nos cuentan las precauciones sanitarias que adoptaban para eludir el contagio: "la hora regular de la visita [a los enfermos] era entre seis y siete de la mañana; antes de entrar a ver a los apestados, nos deteníamos en la Botica, algo distante de aquel recinto [Baluarte de San Julián], mientras por dos, o tres veces se fumigaban con pólvora los cuartos donde residían los enfermos, y demás partes del destinado sitio; practicada a satisfacción esta diligencia, nos mojábamos caras y manos con el vinagre bezoárdico de Barbete; y llevando en la boca un pedazo de alcanfor, entrabamos a visitar los dolientes; sólo nos deteniamos aquel tiempo preciso para informarnos de su estado, y luego que salíamos, nos lavábamos con el referido vinagre, y al punto mudábamos de ropa" (Exarch: 99)

\section{La llegada de la peste negra al Peñón de Vélez de la Gomera}

Pese a lo anterior no parece que se tuvieran muy en cuenta las medidas preventivas en el caso de la llegada de la peste en 1743. Pero analicemos antes el origen de esta epidemia en sus versiones conocidas.

Que la epidemia llegó al Peñón procedente de Ceuta, es sabido, pero el origen de la epidemia es más confuso. Conocemos dos versiones:

1ํ: La peste fue difundida en toda Berbería por "un navío que había dado 
al través junto a Larache, el que venía cargado de tabaco de hoja". (Caro: 166).

2": Atribuye la epidemia de peste en Ceuta a que siendo "el origen de dicho contagio ocasionado por el cadáver de uno de los frailes redentores, falleció en Berbería donde a la sazón se padecía aquella enfermedad y que fue conducido por los moros fronterizos a esta Plaza [Ceuta] para su enterramiento.

La enfermedad duró desde junio del año 1743 hasta septiembre de 1744 y tan grandes debieron ser los estragos que ocasionara que en conmemoración de dicho azote aún se conserva y se celebra anualmente una función religiosa denominada el Voto, instituida en aquella fecha.

Todavía en nuestros días, hemos visto en la cripta del ya derruido Convento de Trinitarios varias sepulturas de dicha época con letreros en las piedras que la servían de cubiertas, prescribiendo que no fuesen abiertas hasta pasados cien años". (García: 121-122).

Sea veraz una versión u otra, lo cierto es que la epidemia ceutí tuvo que ser conocida en el Peñón, y debieron adoptarse medidas de cuarentena, cuando arribó el buque procedente de Ceuta, la noche del 5 de julio de 1743. Es decir, apenas declarada la epidemia en Ceuta. Sin embargo no se adoptaron precauciones, ni siquiera cuando al día siguiente de la llegada del barco se informó de que en él venía un soldado enfermo, que fue trasladaso al hospital, donde murió rápidamente. Al morir sin signos externos del "pestilencial contagio" (bubón, carbunco, petechias) no se adoptaron precauciones. Pero tres días después, la mujer de un cabo de artilleros destacado en la Plaza, y que había llegado en el mismo buque, cayó enferma. Reconocida por el médico de la Plaza y por el cirujano Francisco Beltrán, se dictaminó la aparición del "bubón pestilente", pero descartaron la epidemia al no darse otras manifestaciones. El 28 de julio, dos enfermos del hospital, que habían cuidado al soldado muerto de peste, llamados Diego Guerrero y Bartolomé Amaya, enfermaron, pasando en breve tiempo "de la cama al féretro". Sin embargo, no fue hasta el mes de agosto, en que se manifestó crudamente la epidemia trascendiendo a todo el recinto.

Ante el tumulto desatado en la plaza el propio gobernador obligó a los médicos a emitir públicamente su dictamen. A continuación se envió una falúa a Ceuta para consultar a sus médicos las formas de combatir la epidemia. Con ello se intentó, sin éxito, remediar la situación. Las muertes del médico y del cirujano del Peñón, llevaron al gobernador del Peñón, Julián Fernández-Bayña y Cortés, a escribir a la Junta de Salud de Málaga, solicitando el envío de médicos. Como resultado de esta petición, se desplazaron nuestros tres médicos-escritores al Peñón (Exarch: 29-33). 


\section{Cómo se combate una epidemia de peste negra según tres médicos del siglo XVIII}

Thomás Exarch, Juan de Figueroa y Joseph Serrano, dos médicos y un cirujano, controlaron la epidemia de peste negra, atendiendo tanto a las necesidades físicas como a las espirituales. Esto último respondía a la creencia de que el origen del contagio era, sin duda, un castigo divino, por las condiciones de vida de la Plaza. Este providencialismo cristiano llevó a limosnas, ayunos y disciplina. Pero, para alejar la guadaña de la Parca de los cuellos de los isleños, parecía más efectiva la medicina de nuestros tres médicos. El dictamen que estos emiten es rotundo: "Fiebre pestilente contagiosa al inmediato por fomes". En el libro se explican cada una de estas acepciones suficientemente. Nuestros autores hacen gala de su conocimiento de los autores clásicos (Virgilio; Ovidio; etc.), de los bíblicos y de los tratadistas médicos de la época, junto a los inevitables Hipócrates o Galeno. Como muchos de los lectores de este libro, tengo que afirmar que "Non sun medicus", y por tanto, dejo las disquisiciones a los especialistas, pero desde luego llama la atención las constantes referencias teóricas a los clásicos para afianzar el remedio de las enfermedades.

Como no era posible la huida del Peñón, posiblemente el mejor remedio para los todavía sanos (como en el Decameron, de Bocaccio, que recrea la irrupción de la peste en Italia en 1353), los médicos toman una serie de medidas, en consonancia con los conocimientos de la época. En primer lugar, como creían que el aire corrupto conllevaba la epidemia, buscan purificarlo mediante la quema de árboles de la costa de los gomara. La vegetación era entonces abundante "En las sierras inmediatas [al Peñón] hay muchos árboles de alcornoques, encinas y alerces para hacer bajeles..." (Estrada: 531). Las sierras de El Cantil y la Baba, podían proporcionar la leña necesaria y así utilizar el fuego, considerado entonces como un arcano contra la pestilencia.

Complementando lo anterior, se distribuyeron en las casas vasos llenos de vinagre, juncia, rosa y angélica. "para que los vapores exalados de este compuesto impregnasen los particulares ambientes de ellas y respirándole con esta cualidad, se dispusieran los cuerpos a resistir la pestilencia" (Exarch: 46). Además, autorizados por el gobernador del Peñón, exponen un decálogo de medidas a adoptar, que resumo a continuación (Exarch: 42-43):

1.- Que se destine un sitio para los enfermos, donde no puedan entrar los sanos.

2.- Que la parte del istmo, llamada "La Isleta", sirva para ser ocupada por los convalecientes, en cuarentena. Y que al concluir la cuarentena sean trasladados al lugar denominado "El polvero", hasta su recuperación.

3.- Que se queme todo lo que estuviese en contacto con los contagiados (camas, ropa, etc.) y que el que hurte algo de ello sea anatemizado por el Juez 


\section{Eclesiástico de la Plaza.}

4.- Que se quemen las ropas, camas y tablados del cuartel de los soldados del destacamento, ya que ha sido la gente más frecuentemente contaminada.

5.- Que se haga lo mismo en el Cuartel de Artilleros, ya que la mujer del Cabo, que vino de Ceuta, pudo contagiarlo a tavés de su marido.

6.- Que los mencionados cuarteles no se habiten hasta que se hayan revocado paredes, lavado los techos con vinagre, desenvueltos los pavimentos, y "repetir sahumerios de azufre, mirra y azibar, o en su defecto pólvora", debiendo hacerse lo mismo en las casas de los que han sufrido pestilencia.

7.- Que se enciendan fuegos con la madera de enebros y sabinas de la inmediata costa, y aun quemar pólvora, para purificar la atmósfera.

8.- Que los gatos y perros sean sacrificados, aunque se tengan dudas de que la pestilencia ataque sólo a los seres racionales, pero estos domésticos pueden llevar "de un lugar a otro alguna cosa que sea proporcionado formes, y oculta por casualidad en no frecuentado sitio, darle ocasión para que en lo futuro reproduzca la Lue".

9.- Que se atiende especialmente a la limpieza.

10.- Una vez conseguida la curación, los hospitales destinados para su curación se destechen, piquen sus paredes, y se expongan a una larga ventilación, y siendo posible se reedifiquen de nuevo..."

Este impresionante decálogo de los médicos incide en la importancia de los alimentos. Pero, tuvieron que acomodarse a lo escaso del país, ya que los almacenes sólo tenían, la poco recomendable, carne de puerco. Curiosamente aconsejan ejercicio moderado, previniendo contra "las pasiones de ánimo, de miedo y de tristeza..." (Exarch: 48-49). No en vano, los médicos creían que la mujer estaba más expuesta al contagio "por razón de su sexo". Igualmente, creían que los animales no eran susceptibles del contagio, aunque ello no fue obstáculo para que eliminaran a todos los del Peñón.

Una vez que nuestros médicos han descrito la epidemia y realizado las indicaciones pertinentes para remediarla, pasan a la parte terapéutica, que es compleja y que lleva a disquisiciones en torno a la validez de estas circunstancias de remedios como la sangría, la purga, con sus vómitos, o eméticos y los fármacos o medicamentos en forma de bebida o de píldora o bolos en el caldo. A algunos se "les propinó la piedra bezoar y el espíritu de nitro dulce". Los principales "Alexipharmacos y diaphoreticos" usados fueron: "alcamphor, y su aceite, sal volatil de vivoras, cuerno de ciervo filosófico, la sal volatil de éste, las flores de azufre, el antiminio diaphoretico, el bezoardico mineral, la piedra bezoar, el escordio, el cardo santo, la theriaca magna, el diascordio de Gerónimo Fracastoreo, los vinagres bezoardicos y los espíritus agrios". (Exarch: 63)

Toda esta parte terapeútica continua con citas clásicas que cimentan los remedios y con aforismos, como que "cuanto mas sudor, más esperanza", ya que 
el veneno de la peste había que expulsarlo. La terapeútica iba acompañada de máximas: propinar los alexifarmacos acompañados de agrios, al ritmo de cada ocho horas para que el enfermo no dejara de sudar; y, no permitir el inmoderado sueño durante el sudor; no dejar de rebatir los alexifarmacos sudorificos, aunque los vomitase el enfermo; la última máxima es "a modo de la que vale el diestro general cuando entra en una Plaza, que desmanteló el enemigo, procura levantar los edificios, reedifica las almenas, y construir las fortificaciones, que quedaron demolidas así nosotros, cuando por medio del suficiente sudor juzgábamos que el veneno se había de todo punto puesto en fuga, procurabamos restablecer la debilitada naturaleza, y restituir las fuerzas, en la batalla antecedente perdida. (Exarch: 70)

El libro continúa con el análisis descriptivo de los más horribles síntomas de la peste y concluye con tres historias clínicas, cada una con su "consectario" o corolario.

Historia $~^{a}$ : Hallándose apestados los médicos del Peñón, y otros moradores, piden ayuda a Alhucemas, para el envio, de su médico, hasta que llegase el pedido de Málaga. No se permitió el pasaje al médico, pero el gobernador de Alhucemas envió a un cirujano desterrado, Pascual Soriano, que estaba a la llegada de los tres médicos malagueños y que murió por no adoptar precauciones ante el contagio. Consectario: No tomó precauciones, pero los médicos de Málaga sí: procurando antes de salir de sus casas "tomar alimento de buena sustancia", etc.

Historia $2^{a}$ : Cuenta la historia de Joseph de Flores, que cuidaba, entre otros, a los 23 convalecientes sometidos a cuarentena en la Isleta. Consectario: La bondad de la cuarentena, y una discusión teórica sobre si la peste puede atacar dos veces a una misma persona.

Historia 3ㅁ: La muerte de varios niños por la epidemia y de Felipe del Castillo. Consectario: Al ser todos los muertos de la misma-familia, los médicos afirman que la peste se propaga sólo entre cuerpos de la misma disposición. Siguen afirmando que sólo se propaga entre los racionales.

El libro termina, con un breve epílogo fechado en: Peñón, 18 de diciembre de 1743, y la relación de los tres médicos: "Aquí hace punto la pluma, pues dió los últimos coloridos al dibujo..." 


\section{NUESTRA EDICIÓN}

Nuestra edición respeta íntegramente las características originales del libro. Este se estructura conforme a lo estipulado para las publicaciones de mediados del siglo XVIII. Tras la portada, y la dedicatoria de los autores al gobernador del Peñón, Julián Fernández-Bayña y Cortés (gobernador del Peñón del 20 de julio de 1730 al 4 de febrero de 1755), que incluye su propio escudo heráldico, a modo de ex-libris, vienen los dictámenes: el clerical y el médico. Todo ello hace posible que el libro sea impreso en Málaga y que haya llegado hasta nosotros. De esta manera, el siglo XVIII, conocido como el siglo de las luces, o de la ilustración, uno de los momentos más brillantes de la historia del libro, también tendrá su impronta, en Melilla. Recordemos que en 1748 se imprime la Población General de España..., del melillense Juan Antonio de Estrada y Paredes, obra imprescindible para la historia de Melilla, y verdadera enciclopedia precursora del Diccionario de Pascual Madoz. Además, Melilla genera otras creaciones, como el Diario del Sitio de Melilla, de Francisco de Miranda, e, incluso, opúsculos anónimos como el titulado Expresión lírica de la toma de El Cubo, sitio dominante a Melilla, que hace un efecto numen y dedica a $D$. Antonio de Villalba y a D. Juan Martín Zermeño..., que fechamos en torno a 1734-1736.

En cuanto al propio Peñón, conocemos la obra de Diego de León. Diálogo entre un desterrado del estado del Peñón y el alférez $D$. José León, intérprete de lengua arábiga en dicha plaza que estuvo cautivo 26 años en Mequinez, sobre la vida de Mulay Ismail, rey de Fez, fechado hacia 1728 (Morales: 351)

Por otra parte, los estudios actuales sobre las epidemias de peste negra en el siglo XVIII, y sus incidencias demográficas, sociales, económicas, artísticas etc., podemos observar, por la aparición de publicaciones recientes, la vigencia que tienen.

Así, a destacar el enciclopédico y complejo trabajo de Enrique Jarque Ros, Estudios de geografía e historia médica de Ceuta: historiografía general de la peste. La peste bubónica y Ceuta, publicado por el Ayuntamiento de Ceuta en 1988. Este libro trata intensamente, en sus más de cuatrocientas páginas, la cuestión de estas pandemias, y, entre ellas, a la epidemia de 1743-1744. Los aportes bibliográficos, documentales, $y$, especialmente, iconográficos, hacen de este ensayo un auténtico tratado sobre la cuestión.

Igualmente, y en el curso de la celebración del II Congreso Internacional sobre el Estrecho de Gibraltar (Ceuta, 19 a 22 de noviembre de 1990) fue presentada la comunicación La epidemia de Ceuta de 1744 y sus consecuencias para la vida de la ciudad, por Marta González Quintana.

Ya, para situar la epidemia en su contexto geográfico, ha sido leida en junio de 1990 la tesis de doctorado de estado de Mohamed Amine Bezzaz, en la Facultad de Letras de Rabat, con el título de Famines et epidemies en Maroc aux 
$X V I I I^{e}$ et $X I X^{e}$ siècles. Esta tesis fue reseñada, por el profesor marroquí Germain Ayahe, recientemente fallecido, en Revue Dar al-Niaba: etudes d' histoire morocaine, № 26/27, Tánger, 1990, p. 2-4, e, igualmente, por el profesor del Instituto de Demografía de París, Mohamed M'rabet, en las páginas 5 a 22 de la misma revista.

En suma, el libro que exponemos, en edición facsímil que reproduce fielmente el libro original, y que fue escrito originariamente en latín por nuestros tres cultos médicos, y, posteriormente traducido a la lengua de Cervantes, consiguiendo así mayor difusión, para que, como dice uno de los censores del libro, "corra pues esta obra por todo el espacioso ámbito del mundo", guarde entre sus páginas festoneadas con los punzones del setecientos, un ensayo de medicina, historia y literatura. La facundia de sus autores y la belleza del castellano del siglo XVIII, aunque sea como soporte de un tema a veces alejado del profano, hacen posible el deleite. La peste negra, una de las epidemias más terribles de los tiempos idos, a modo de jinete apocalíptico, queda descrita a la luz de los conocimientos de la medicina del momento. Nuestros autores recurren a los clásicos, pero también acopian los descubrimientos modernos y los autores que como el médico italiano Girolano Fracastoro, precedieron a su época, al exponer novedosos mecanismos del contagio, en su libro De contagione et contagiosis morbis (1546). Francastoro, más famoso por su poema Syphilis sive de morbo gallico (1530), es un ejemplo de anticipación a los conocimientos y la praxis de su época.

Las victimas de la epidemia quedaron pues en el Peñón para siempre, enterradas en el baluarte de San Julián, y no en el cementerio de la Concepción, que había sustituído al de la iglesia parroquial, utilizado profusamente hasta el siglo XVIII (Morales: 397). Los que sobrevivieron pudieron ver la construcción de una nueva epidemia de landre en octubre de 1745. Quizá por ello se construyó un nuevo hospital en 1747. Pero, todavía quedaban para el Peñón periodos muy duros de catástrofes de todo tipo y, posiblemente, en más de un "isleño" resonaría en horas bajas la estrofa de Pedro Calderón de la Barca, en su Autos sacramentales:

\author{
"Fatigado peregrino \\ que como apestado haces \\ cuarentena en un desierto \\ sujeto a la sed y a la hambre"
}

Sin duda, para los esforzados habitadores del Peñón, la cuarentena sería secular y permanente, escasa de agua, deficiente en alimentos y sometida al arcano de su presencia invisible en la costa norte de Africa: Atalaya del Rif. 


\section{NOTAS BIBLIOGRÁFICAS}

AREJULA, Juan Manuel de. Sucinta exposición de la enfermedad contagiosa que reina epidémicamente en esta plaza de Málaga, síntomas con que se ha presentado, y método curativo que hemos empleado. Córdoba, 1804.

AREJULA, Juan Manuel de. Memoria presentada a la Junta de Sanidad de Málaga. Córdoba, 1802.

CARO, Lucas. Historia de Ceuta. Ceuta, 1989 (1‥ ed., c. 1800).

CRESSIER, Patrice. "Fortifications du Rif". En: Habitats fortifiés et organisation de l'espace en Mediterranée médiévale: table ronde tenue a Lyon les 4 et 5 mai 1982 [extrait]. Madrid, 1983.

ESTRADA, Juan Antonio de. Población general de España. Madrid, 1748, 3 v. EXARCH, Thomas, FIGUEROA, Juan de, y SERRANO, Joseph. El contagio de El Peñón... Málaga, 1744.

GARCÍA FERNÁNDEZ, Celestino. Geografía médica de Ceuta, Ceuta 1987

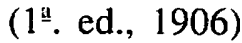

MADOZ, Pascual. "Melilla \& las plazas menores (Chafarinas; Vélez de la Gomera; Alhucemas) en el Diccionario Geográfico-Estadístico-Histórico de España y sus posesiones de ultramar" En Aldaba: Revista del Centro Asoci

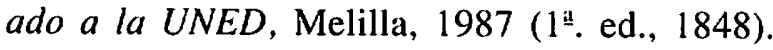

MAROC: Hachette guides bleus. París, 1983.

MORALES Y MENDIGUTIA, Gabriel de. Efemérides y curiosidades: Melilla, Peñón y Alhucemas. Melilla, 1920.

PALLARES, Juan Gabriel. Islas para descubrir el Mediterráneo. Madrid, 1988. PEZZI, Rafael. Los presidios menores de Africa y la influencia española en el Rif. Madrid, 1893.

SANZ SAMPELAYO, Juan. Los presidios españoles del Norte de Africa y su aprovisionamiento de víveres a fines del siglo XVIII. Granada, 1977-1978. ZIÏM, Fonad. "Le Maroc Méditerranéen an XIXe siède on la Frontière intérieure". En: Revue de l'Occident musulman et la Méditerranée, Aix-en-Provence, 1988, no 2-3. 


\section{DICCIONARIO AUXILIAR DE ALGUNAS VOCES MÉDICAS RECOGIDAS EN "EL CONTAGIO DE EL PEÑÓN"}

* Fomes: La causa que nos excita y mueve a hacer alguna cosa. En El Contagio de El Peñón se define como "a cualquier cuerpo que envolviendo en su textura los pestilentes efluvios, comunica a proporcionado viviente el daño, que aunque le tiene, por su incapacidad no le ofende". Es decir el "Fomes" es la forma de contagio de la peste.

* Fomes pecati: La inclinación o propensión que naturalmente tenemos a lo malo, heredada del pecado de nuestros primeros Padres; la cual se debe vencer con el santo temor de Dios.

* Landre: Especie de seca o tumor de la hechura y tamaño de una bellota, que se hace en los sobacos y en las ingles; y suele muy de ordinario dar esta enfermedad en la garganta y ahogar con brevedad al paciente. Es voz corrompida de Glande, de donde trae su origen.

* Lazareto: Hospital o casa en los puertos de mar, fuera de la población, en lugar cómodo, donde se hace hacer la cuarentena a los que vienen de parajes sospechosos de peste.

* Lúe o Lúes: Antigüamente cualquier enfermedad contagiosa. Así, la sífilis o lúe venérea.

* Peste: Enfermedad contagiosa ordinariamente mortal y que causa muchos estragos en las vidas de los hombres y de los brutos. Ocasiónase por lo común de la infección, del aire, y suelen ser la señal de ella unos bultos que llaman bubones u landres.

* Physico: En lo antiguo se llamaba al médico. (La más alta instancia de la medicina en el siglo XVIII la constituían los protomédicos, expresión que incluía tanto a médicos muy importantes, como, propiamente, a los tres médicos del Rey que componen el tribunal del protomedicato, encargados de designar a los nuevos médicos. El cirujano, ejercía el arte de la cirujía. Barberos, boticarios, sangradores, etc., completaban el panorama médico sanitario de la época).

* Púrpura: Hemorragia cutánea y mucosa por roturas vasculares. Si las manchas son pequeñas se llaman petequias.

Nota.- La mayoría de las expresadas definiciones han sido tomadas de: REAL ACADEMIA ESPAÑOLA. Diccionario de autoridades. Madrid, 1963, 3 v. (edición facsimil de la 1‥ ed., 1732). Para un glosario mucho más completo, véase la obra de Enrique Jarque Ros, anteriormente citado, especialmente las páginas 359 a 395. 